\title{
Influence of breast reconstruction on technical aspects of echocardiographic image acquisition compared with physician-assessed image quality
}

Joaquin Duarte Ow¹, Mohamad Hemu², Anel Yakupovich², Parva Bhatt ${ }^{2}$, Hannah Gaddam³ ${ }^{2}$ Nicole Prabhu², Ibtihaj Fughhi ${ }^{2}$, Melody Cobleigh ${ }^{4}$, Melissa Tracy ${ }^{5}$, Louis Fogg ${ }^{6}$ and Tochukwu Okwuosa ${ }^{5^{*}}$ (D)

\begin{abstract}
Introduction: Assessment of cardiac function after treatment for breast cancer relies on interval evaluation of ventricular function through echocardiography. Women who undergo mastectomy more frequently choose to undergo breast reconstruction with implant. This could impede assessment of cardiac function in those with leftsided implant. We aimed to examine whether left-sided breast reconstruction with tissue expanders (TE) affect echo image acquisition and quality, possibly affecting clinical decision-making.

Methods: A retrospective case-control study was conducted in 190 female breast cancer patients who had undergone breast reconstruction with TE at an urban academic center. Echocardiographic technical assessment and image quality were respectively classified as excellent/good or adequate/technically difficult by technicians; and excellent/good or adequate/poor by 2 board-certified cardiologist readers. Likelihood ratio was used to test multivariate associations between image quality and left-sided TE.

Results: We identified 32 women (81.3\% white; mean age 48 years) with left-sided/bilateral TE, and 158 right-sided/ no TE (76.6\% white, mean age 57 years). In multivariable analyses, we found a statistically significant difference in technician-assessed difficulty in image acquisition between cases and controls $(p=0.01)$; but no differences in physician-assessed image quality between cases and controls ( $p=0.09$, Pearson's $r=0.467)$.

Conclusions: Left-sided breast TE appears to affect the technical difficulty of echo image acquisition, but not physician-assessed echo image quality. This likely means that echo technicians absorb most of the impediments associated with imaging patients with breast TE such that the presence of TE has no bearing on downstream clinical decision-making associated with echo image quality.
\end{abstract}

Keywords: Echocardiogram, Image quality, Breast reconstruction, Tissue expander

\section{Introduction}

Cardiovascular disease is an important cause of morbidity and mortality in cancer patients. In particular, chemotherapy and chest radiation therapy increase the risk of cardiotoxicity; including cardiomyopathy and heart failure, coronary artery disease, pericardial disease,

\footnotetext{
* Correspondence: tokwuosa@rush.edu

${ }^{5}$ Division of Cardiology, Rush University Medical Center, 1717 West Congress Parkway, Kellogg Bldg, Suite 328, Chicago, IL 60612, USA

Full list of author information is available at the end of the article
}

valvular dysfunction, and conduction abnormalities [1-3]; and may persist up to 45 years after therapy [1].

Although advances in breast cancer treatment have reduced its toxicity and increased survival, breast cancer survivors are still at increased risk of myocardial and coronary dysfunction due to prior cancer therapy $[2,3]$. When breast cancer is detected at an early stage, the treatment usually involves surgery; with options for breast preservation or mastectomy. Increasingly, women undergo mastectomy [4], either because of personal preference, hereditary predisposition to breast cancer or

(c) The Author(s). 2019 Open Access This article is distributed under the terms of the Creative Commons Attribution 4.0 International License (http://creativecommons.org/licenses/by/4.0/), which permits unrestricted use, distribution, and reproduction in any medium, provided you give appropriate credit to the original author(s) and the source, provide a link to the Creative Commons license, and indicate if changes were made. The Creative Commons Public Domain Dedication waiver (http://creativecommons.org/publicdomain/zero/1.0/) applies to the data made available in this article, unless otherwise stated. 
because magnetic resonance imaging detects multicentric disease. Women who chose mastectomy are increasingly undergoing reconstruction [4]; the most common reconstructive procedure is tissue expansion, followed by insertion of a permanent implant [5]. There is extensive research that relies on echocardiography (echo) and other cardiac imaging modalities to determine early markers of cardiotoxicity in cancer survivors $[6,7]$. Echocardiography is deemed the technique of choice when undertaking a global comprehensive assessment of cardiac structure and function at baseline and during the cancer process [8]. Different guidelines have different intervals for cardiac assessment via echo in cancer survivors that can range from 6 to 18 months after the last chemotherapy [8-10].

The acquisition of good quality echocardiographic images in post-mastectomy, breast cancers survivors after left breast implant insertion is important because echocardiography is one of the most readily available and utilized tests to assess myocardial function. MUGA is another imaging modality employed in the assessment of left ventricular function in cancer patients; however, this modality increases radiation exposure as compared to echocardiographic imaging. Furthermore, unlike MUGA, echocardiography is highly comprehensive and assesses cardiac structure and function without associated radiation risk. However, the importance of echocardiography in the detection of myocardial toxicity in cancer survivors combined with the increase in breast reconstruction [11] leads us to a potential new challenge in cardiac surveillance of these patients - the interference of breast implants in the acquisition of a good acoustic window in ultrasound $[12,13]$.

We aimed to assess whether the effects of breast reconstruction on echocardiographic image quality could ultimately influence clinical decision-making. In this study, we examined the effects of left-sided breast reconstruction with tissue expanders (TE) on echocardiographic image acquisition; and its downstream effects on image quality.

\section{Methods}

\section{Study population}

We conducted a case-control study in a population of female patients, age $>18$ years, with biopsy-proven breast cancer, diagnosed between 1990 and 2015, and treated surgically at Rush University Medical Center (RUMC). Surgical treatments included mastectomy/ lumpectomy and reconstruction with TE. All patients had echocardiographic follow up after mastectomy. Patients with metastatic disease at diagnosis were excluded from our study. The study was approved by RUMC institutional Review Board.

\section{Patient selection}

A total of 190 patients meeting both inclusion and exclusion criteria were identified from the electronic medical record system (EPIC) - Fig. 1. The case group consisted of patients with a left-sided TE (left-sided only or bilateral); and the control group were those without a left-sided TE (right-sided or no reconstruction).

The study variables (Table 1) were extracted from the RUMC electronic medical record and stored in the REDCap database software. After chart review was completed, the information was exported to SPSS software for statistical analysis.

\section{Tissue expanders characteristics}

TE used were constructed from silicone elastomer made of polydimethylsiloxane. These expanders were inflated with saline to obtain the desired size prior to implantation. TE were available in either smoothed or textured surface shells. They were made of cohesive gel that holds uniformly together and takes the natural shape of the breast (model Mentor MemoryShape). The majority of patients had TE implanted in a retro-pectoral position.

\section{Echocardiographic data}

Echocardiographic images were obtained using four major positions: the apical, parasternal, suprasternal notch and subcostal views. This was based on the standard set of views as recommended by the American Society of Echocardiography [14]. Studies were performed by highly skilled echocardiography technicians with long standing experience at a tertiary care center. All examinations were conducted using GE (Vivid-7) and Phillips (IE-33) echocardiographic machines.

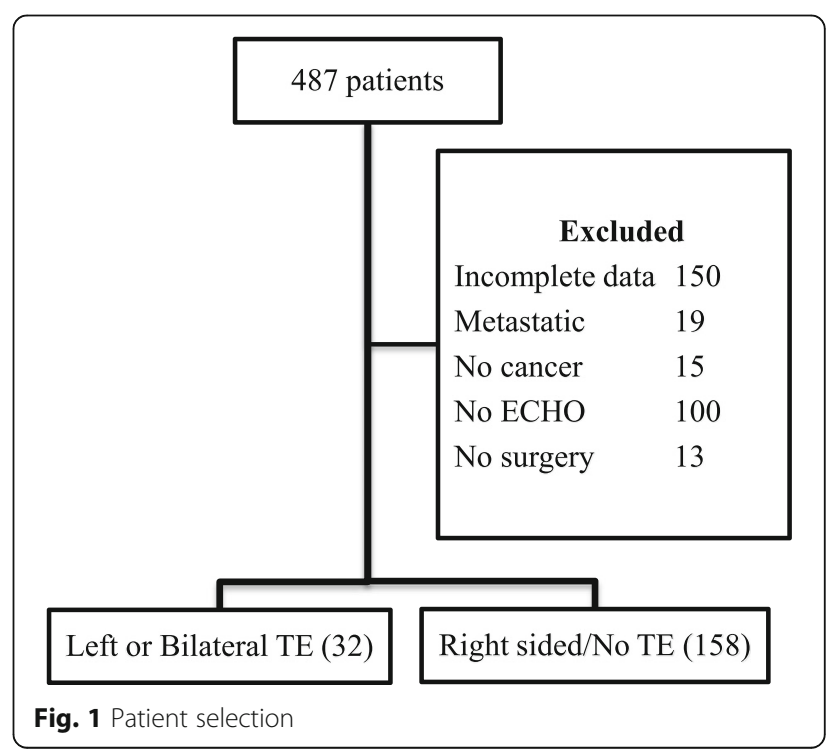


Table 1 Baseline characteristics

\begin{tabular}{|c|c|c|c|c|c|}
\hline \multirow[b]{2}{*}{ Race } & \multicolumn{2}{|c|}{$\begin{array}{l}\text { Left/Bilateral } \\
\text { TE }\end{array}$} & \multicolumn{2}{|c|}{$\begin{array}{l}\text { Right/No } \\
\text { recontstruction TE }\end{array}$} & \multirow[t]{2}{*}{$p$ value* } \\
\hline & & & & & \\
\hline Non-white & (6) & $18.7 \%$ & (37) & $23.4 \%$ & \\
\hline White & (26) & $81.3 \%$ & (121) & $76.6 \%$ & \\
\hline
\end{tabular}

Breast Cancer

\begin{tabular}{|c|c|c|c|c|c|}
\hline \multicolumn{6}{|l|}{ Primary side } \\
\hline Right & (9) & $28.2 \%$ & (74) & $46.8 \%$ & \\
\hline Left & (23) & $71.8 \%$ & (79) & $50 \%$ & \\
\hline Bilateral & (1) & $2 \%$ & (5) & $3.2 \%$ & \\
\hline Size & & & & & 0.010 \\
\hline $2-5 \mathrm{~cm}$ & (8) & $25 \%$ & (40) & $25.3 \%$ & \\
\hline$>5 \mathrm{~cm}$ & (5) & $15.6 \%$ & (6) & $3.7 \%$ & \\
\hline Chest or skin invasion & (1) & $3.2 \%$ & (1) & $0.6 \%$ & \\
\hline Not specified & (1) & $3.2 \%$ & (9) & $5.6 \%$ & \\
\hline Node status & & & & & 0.329 \\
\hline No & (14) & $43.7 \%$ & (83) & $52.5 \%$ & \\
\hline N1 & (18) & $56.3 \%$ & (73) & $46.2 \%$ & \\
\hline Grade & & & & & 0.633 \\
\hline । & (3) & $9.4 \%$ & (22) & $14.2 \%$ & \\
\hline$\|$ & (18) & $25 \%$ & (41) & $26.5 \%$ & \\
\hline III & (16) & $50 \%$ & (56) & $36.1 \%$ & \\
\hline Not specified & (7) & $15.6 \%$ & (36) & $23.2 \%$ & \\
\hline \multicolumn{6}{|l|}{ TE side } \\
\hline Left & (14) & $7.4 \%$ & & & \\
\hline Right & & & (7) & $3.4 \%$ & \\
\hline Bilateral & (18) & $9.4 \%$ & & & \\
\hline No reconstruction & & & (151) & $79.4 \%$ & \\
\hline \multicolumn{6}{|l|}{ Treatment } \\
\hline Anthracyclines & (28) & $90.2 \%$ & (104) & $70.7 \%$ & 0.049 \\
\hline Antiestrogen & (25) & $78.1 \%$ & $(100)$ & $68 \%$ & 0.248 \\
\hline Trastuzumab & (29) & $90.6 \%$ & (105) & $70.9 \%$ & 0.012 \\
\hline Radiation Therapy & (29) & $90.6 \%$ & (104) & $71.2 \%$ & 0.001 \\
\hline \multicolumn{6}{|l|}{$\mathrm{ECHO}$} \\
\hline LVEF & $58 \pm$ & & $58 \pm 7$ & & 0.913 \\
\hline $\mathrm{BMI}$ & $26.9=$ & \pm 5.4 & $28.7 \pm 7.3$ & & 0.242 \\
\hline SBP & $123 \pm$ & $=18$ & $131 \pm 22$ & & 0.051 \\
\hline DBP & $71 \pm$ & & $73 \pm 12$ & & 0.350 \\
\hline \multicolumn{6}{|l|}{ Comorbidities } \\
\hline COPD & - & & (8) & $5 \%$ & 0.016 \\
\hline Prior Chest surgery & (3) & $9.7 \%$ & (13) & $8.4 \%$ & 0.826 \\
\hline HTN & (16) & $51.6 \%$ & (87) & $56.5 \%$ & 0.618 \\
\hline DM & (3) & $9.4 \%$ & (25) & $16.2 \%$ & 0.300 \\
\hline Dyslipidemia & (8) & $25 \%$ & (49) & $32 \%$ & 0.427 \\
\hline
\end{tabular}

Table 1 Baseline characteristics (Continued)

\begin{tabular}{|c|c|c|c|c|c|}
\hline \multirow[b]{2}{*}{ Heart failure } & \multicolumn{2}{|c|}{$\begin{array}{l}\text { Left/Bilateral } \\
\text { TE }\end{array}$} & \multicolumn{2}{|c|}{$\begin{array}{l}\text { Right/No } \\
\text { recontstruction TE }\end{array}$} & \multirow{2}{*}{$\frac{p \text { value }^{*}}{0.419}$} \\
\hline & (2) & $6.5 \%$ & (17) & $11 \%$ & \\
\hline CKD & (1) & $3.2 \%$ & (4) & $2.6 \%$ & 0.852 \\
\hline$C A D$ & (1) & $3.2 \%$ & (17) & $11 \%$ & 0.278 \\
\hline Obesity & (17) & $32.7 \%$ & (73) & $36.9 \%$ & 0.879 \\
\hline \multicolumn{6}{|l|}{ Medications } \\
\hline ASA & (7) & $21.9 \%$ & (45) & $29.2 \%$ & 0.390 \\
\hline ACE/ARB & (8) & $25 \%$ & (38) & $24.7 \%$ & 0.969 \\
\hline Beta blocker & (8) & $25 \%$ & (47) & $30.5 \%$ & 0.528 \\
\hline Statin & (9) & $28.1 \%$ & (44) & $28.8 \%$ & 0.942 \\
\hline Smoking & & & & & 0.615 \\
\hline Never smoker & (16) & $53.3 \%$ & (80) & $57.6 \%$ & \\
\hline Former Smoker & (11) & $36.7 \%$ & (52) & $37.4 \%$ & \\
\hline Active Smoker & (3) & $10 \%$ & (7) & $5.9 \%$ & \\
\hline
\end{tabular}

${ }^{*} p$ values $<0.05$ are listed in boldface

Echocardiographic image quality assessment

Data regarding the technician assessment of the technical difficulty of the echocardiographic image acquisition was obtained from the report; excellent, good, adequate, technically difficult (Table 2). The echocardiographic images were subsequently independently reviewed and rated by 2 board certified cardiologists who were blinded to the patient's history and technician rating. The image qualities were assigned by the cardiologists as a rating of excellent, good, fair, or poor image quality (Table 2). The scales used by both the technicians and cardiologists are subjective.

\section{Statistical analysis}

Baseline characteristics were obtained for each of the study groups. Categorical variables were summarized as percentages and absolute numbers; and continuous variables as mean \pm standard deviation. Echocardiographic technical assessment and image quality were respectively classified as excellent/good or adequate/technically difficult by technicians; and excellent/good or adequate/poor by 2 board-certified cardiologist readers. Interpretations were derived from sonographer assessed technical difficulty of the study, and 2 board-certified cardiologists' assessment of image quality. Likelihood ratio was used to

Table 2 Technician and cardiologists assessment scale ${ }^{a}$

\begin{tabular}{ll}
\hline Technical difficulty (Technicians) & Image quality (Cardiologists) \\
\hline Excellent & Excellent \\
Good & Good \\
Adequate & Fair \\
Technically difficult & Poor
\end{tabular}

${ }^{a}$ Technicians assess technical difficulty of image acquisition, cardiologists assess image quality 
test associations between image quality and left-sided TE. The results were adjusted for age, anthracycline/trastuzumab use, radiotherapy, COPD and size of tumor; since these covariates were shown to be different between study groups. Agreement between cardiologists was determined by Pearson's correlation coefficient. The data was streamlined to report findings from one of the cardiologist echo readers. Statistical significance was set at $p<0.05$.

\section{Results}

There were 32 cases and 158 controls. Table 1 shows the baseline characteristics of the study groups. The patient population was mostly white $(77 \%)$. The mean age was $48 \pm 12$ for the study group and $57 \pm 11$ for the control group; and the mean BMI for the study group was $26.9 \pm 5.4$, and $28.7 \pm 7.3$ for the control group. There was no difference between groups in tumor grade, node status, smoking status, LVEF, medications and most comorbid conditions.

There were significant differences in age, tumor size, COPD status and treatment received; specifically, anthracyclines, radiotherapy and trastuzumab between groups.

The technicians rated $9.4 \%$ cases as excellent/good and $90.6 \%$ as adequate/technically difficult; and rate $29.1 \%$ controls as excellent/good and $70.9 \%$ as adequate/ technically difficult $(\mathrm{LR}=6.47, p=0.01)-\mathrm{Fig}$. 2 /Table 3 . On the other hand, the cardiologists rated $31.8 \%$ cases as excellent/good and $68.2 \%$ as fair/poor; and rated $51.2 \%$ controls as excellent/good and $48.8 \%$ as fair/poor $(\mathrm{LR}=2.88 p=0.09)-$ Fig. $2 /$ Table 3. Multivariate analysis showed a relationship dependent on implant side (left/bilateral vs right/none) even when adjusted for age, tumor size, COPD status and treatment received (anthracyclines, radiotherapy and trastuzumab). The Pearson's correlation coefficient $(r)$ between both cardiologist readers $=0.467$. Our study findings were essentially unchanged when image quality data from the second echo reader were used for analysis.

\section{Discussion}

We found significant differences in the technical difficulty of image acquisition as rated by echo technicians when comparing left/bilateral TE to a right-sided/no TE group. Interestingly, this did not translate to physicianassessed image qualities of the same studies. As such, we found no significant difference in image quality as assessed by cardiologists when comparing left/bilateral TE to a right-sided/no TE group.

Our study is unique in that we evaluated both the technical difficulty of the acquired studies as assessed by the echo technicians, as well as image quality reviewed by our experienced cardiologist echo readers. To our knowledge, this is the first study to have examined both in patients post breast reconstruction; and possibly has implications for clinical decision-making. In addition, our study focused on breast tissue expanders particularly (rather than all reconstructive techniques).

Our results are different from the findings from a previous study by Pignati et al. [15] in which patients with left-sided/bilateral tissue expanders had significantly poorer image quality. In that retrospective study, from 2000 to 2012, 44 women post breast reconstruction after mastectomy for breast cancer, were divided in 2 groups: left/bilateral vs right breast implant (control group). In the study group, it was judged as adequate in only $50 \%$ of cases (15 patients) vs. $100 \%$ of the controls ( $p<$ $0.001)$. There could be a number of explanations for the differences in both study findings. Ours was a larger study including more patients. Furthermore, our study

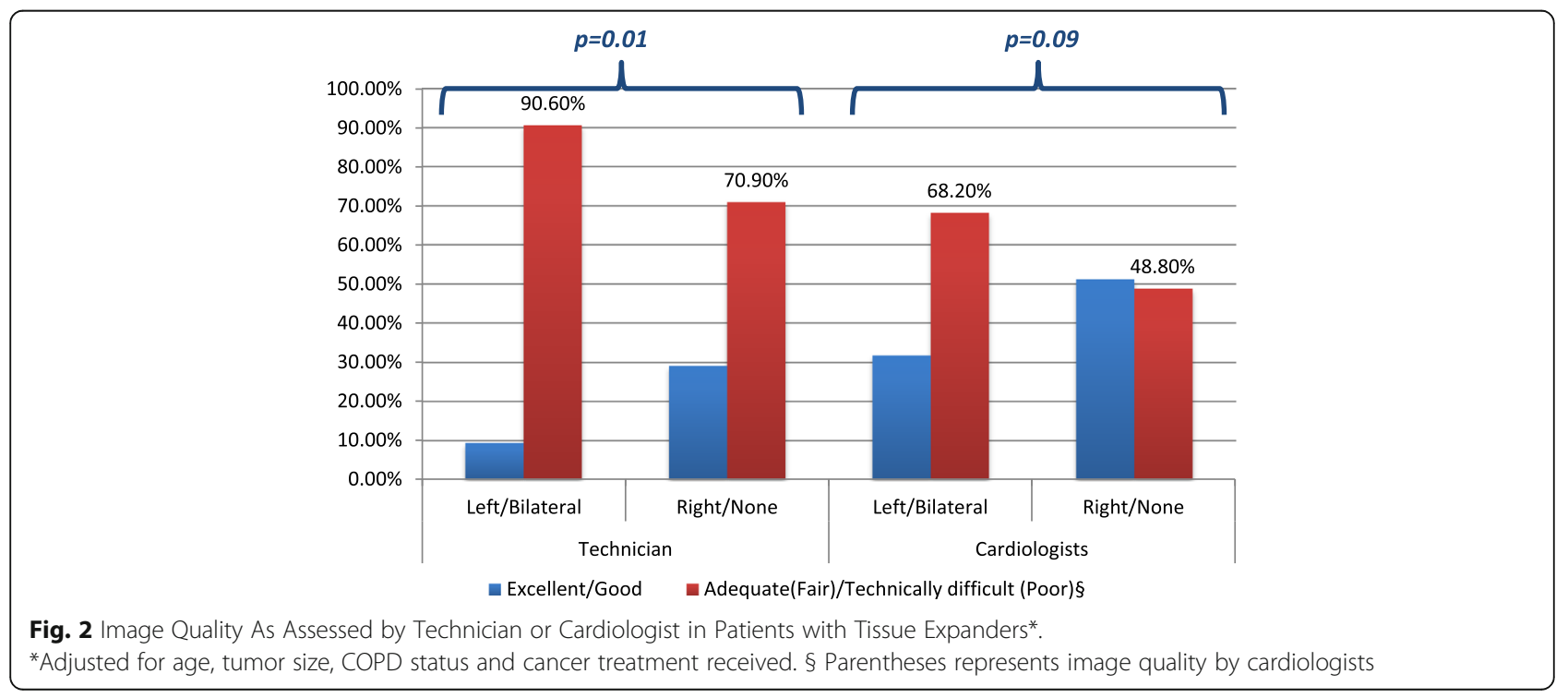


Table 3 Image quality ratings ${ }^{a}$

\begin{tabular}{|c|c|c|c|c|}
\hline & \multicolumn{2}{|l|}{ Technician } & \multicolumn{2}{|l|}{ Cardiologist } \\
\hline & Excellent/Good & Adequate/ technically difficult & Excellent/Good & Fair/Poor \\
\hline Left/Bilateral & $9.4 \%$ & $90.6 \%$ & $31.8 \%$ & $68.2 \%$ \\
\hline Right/None & $29.1 \%$ & $70.9 \%$ & $51.2 \%$ & $48.8 \%$ \\
\hline
\end{tabular}

Adjusted for age, tumor size, COPD status and treatment received (anthracyclines, radiotherapy and trastuzumab

${ }^{a}$ Expressed as percentage of cases or controls

was more rigorous and parsimonious as the echocardiographic image qualities in our study were assessed by only 2 independent cardiologists.

As mentioned, many women are choosing breast reconstruction after mastectomy as evidenced by an increase in breast reconstruction procedures [5]. This trend raised an important clinical question in the surveillance of this patient population since the effects of breast implants on the quality of acquired echo images have been described in case reports $[12,13]$. We decided to study this effect by assessing not only the impact of TE on the acquisition of good-quality echocardiographic images, but also the effects on physician interpretation.

The heart is located in the left pectoral area; as such, most of echocardiographic imaging involves the left chest. It therefore follows that procedures that involve the left-side of the chest (including left breast, whether purely left-sided or bilateral) are more likely to impact cardiac imaging, while no chest procedures or those that purely involve the right breast or right side of the chest are not.

Our study suggests that while the technicians found the presence of breast TE to increase the technical difficulty for performance of the studies, they were able to adequately complete the studies such that the cardiologist echo readers were able to visualize the cardiac structures and rate them as better image quality. This may suggest that well-trained sonographers can overcome the intricacies of echocardiographic imaging associated with breast $\mathrm{TE}$, and thereby prevent possible inadequate and incompetent clinical decision-making as a consequence of poor quality images. This has particular relevance in the population of patients with breast cancer whom might receive cardiotoxic chemotherapy such as anthracyclines and/or trastuzumab as well as radiation therapy, in whom (sometimes frequent) cardiac monitoring with echocardiography is paramount.

In our study, the case group had larger tumors and younger ages and accordingly received more anthracyclines, radiotherapy and trastuzumab. Larger and aggressive tumors are more likely to undergo systemic therapy, and less likely to undergo surgery. Multivariate analysis showed a relationship dependent on implant side (left/bilateral vs right/none) even when adjusted for age, tumor size, COPD status and treatment received (anthracyclines, radiotherapy and trastuzumab). A separate analysis was run with the ungrouped categories of technical assessment and image quality (Table 3); no significant difference was found between technical assessment or image quality and study group.

The limitations of our study include the number of patients excluded due to lack of information during the initial screening, lack of randomization, and the retrospective nature of the study. Another limitation is the fact that the scales utilized for technical difficulty and image quality assessment are based on subjective assessments. The categories were grouped to simplify reporting and increase the amount of subjects per group.

\section{Conclusion}

Left-sided breast TE appears to affect the technical difficulty of echocardiographic image acquisition, but not physician-assessed echocardiographic image quality. This likely means that echo technicians absorb most of the imaging complexities associated with breast $\mathrm{TE}$, resulting in far less significant implications of breast tissue expanders on downstream clinical decision-making associated with echocardiographic image quality. This likely has significant implications for quality of care in breast cancer patients who often require echocardiographic monitoring of cardiovascular structure and function due to prior chemo- and/or radiation therapy.

\section{Acknowledgements}

The authors would like to thank the echo lab technicians for their dedication to accurate and efficient patient imaging.

\section{Authors' contributions}

JDO: Data collection, statistical analysis, drafting and editing of manuscript. $\mathrm{MH}$ : Drafting and editing of manuscript. AY: Data collection, editing of manuscript. PB: Data collection, editing of manuscript. HG: Editing of manuscript, NP: Editing of manuscript. IF: Study conceptualization, data collection, editing of manuscript. MC: Study conceptualization, editing of manuscript. MT: Review of echo images, editing of manuscript. LF: Statistical analysis. TO: Study conceptualization, review of echo images, data collection and analysis, drafting and editing of manuscript. All authors read and approved the final manuscript.

\section{Funding}

N/A

\section{Availability of data and materials}

Yes

Ethics approval and consent to participate Yes 


\section{Consent for publication}

Yes

\section{Competing interests}

The authors declare that they have no competing interests.

\section{Author details}

'Department of Internal Medicine, John H. Stroger, Jr. Hospital of Cook County, Chicago, IL, USA. ${ }^{2}$ Department of Internal Medicine, Rush University Medical Center, Chicago, IL, USA. ${ }^{3}$ University of Illinois at Urbana-Champaign, Champaign, IL, USA. ${ }^{4}$ Department of Hematology/Oncology, Rush University Medical Center, Chicago, IL, USA. ${ }^{5}$ Division of Cardiology, Rush University Medical Center, 1717 West Congress Parkway, Kellogg Bldg, Suite 328, Chicago, IL 60612, USA. ${ }^{6}$ Department of Community, Systems and Mental Health Nursing, College of Nursing, Rush University Medical Center, Chicago, IL, USA.

Received: 13 July 2019 Accepted: 4 October 2019

Published online: 04 November 2019

\section{References}

1. Reulen RC, Winter DL, Frobisher C, et al. Long-term cause-specific mortality among survivors of childhood cancer. JAMA. 2010;304(2):172-9. https://doi. org/10.1001/jama.2010.923.

2. Bradshaw PT, Stevens J, Khankari N, Teitelbaum SL, Neugut Al, Gammon MD. Cardiovascular disease mortality among breast Cancer survivors. Epidemiology. 2016;27(1):6-13. https://doi.org/10.1097/EDE. 0000000000000394

3. Hooning MJ, Botma A, Aleman BMP, et al. Long-term risk of cardiovascular disease in 10-year survivors of breast cancer. J Natl Cancer Inst. 2007;99(5): 365-75. https://doi.org/10.1093/jnci/djk064.

4. Kummerow KL, Du L, Penson DF, Shyr Y, Hooks MA. Nationwide trends in mastectomy for early-stage breast cancer. JAMA Surg. 2015;150(1):9-16. https://doi.org/10.1001/jamasurg.2014.2895.

5. 2011 Plastic Surgery Statistics Report. http://www.plasticsurgery.org/Documents/ news-resources/statistics/2011-statistics/2011_Stats_Full_Report.pdf. Accessed 1 Mar 2014.

6. Armstrong GT, Plana JC, Zhang N, et al. Screening adult survivors of childhood cancer for cardiomyopathy: comparison of echocardiography and cardiac magnetic resonance imaging. J Clin Oncol. 2012;30(23):2876-84. https://doi.org/10.1200/JCO.2011.40.3584.

7. Plana JC, Galderisi M, Barac A, et al. Expert consensus for multimodality imaging evaluation of adult patients during and after cancer therapy: a report from the American Society of Echocardiography and the European Association of Cardiovascular Imaging. J Am Soc Echocardiogr. 2014;27(9): 911-39. https://doi.org/10.1016/j.echo.2014.07.012.

8. Virizuela JA, García AM, de Las PR, et al. SEOM clinical guidelines on cardiovascular toxicity (2018). Clin Transl Oncol. 2019;21(1):94-105. https:// doi.org/10.1007/s12094-018-02017-3.

9. Armenian SH, Lacchetti C, Barac A, et al. Prevention and monitoring of cardiac dysfunction in survivors of adult cancers: American Society of Clinical Oncology clinical practice guideline. J Clin Oncol. 2017;35(8):893911. https://doi.org/10.1200/JCO.2016.70.5400.

10. Carlyn T, Denlinger C. Cardiovascular Toxicity in Cancer Survivors: Current Guidelines and Future Directions. 2018. https://www.acc.org/latest-incardiology/articles/2018/06/29/12/57/cv-toxicity-in-cancer-survivors.

11. Albornoz CR, Bach PB, Mehrara BJ, et al. A paradigm shift in U.S. breast reconstruction: increasing implant rates. Plast Reconstr Surg. 2013;131(1):1523. https://doi.org/10.1097/PRS.0b013e3182729cde.

12. Movahed M-R. Interference of breast implants with echocardiographic image acquisition and interpretation. Cardiovasc Ultrasound. 2007;5:9. https://doi.org/10.1186/1476-7120-5-9.

13. Movahed M-R. Impairment of echocardiographic acoustic window caused by breast implants. Eur J Echocardiogr. 2008;9(2):296-7. https://doi.org/10. 1016/j.euje.2006.10.006.

14. Reeves ST, Glas KE, Eltzschig $\mathrm{H}$, et al. Guidelines for performing a comprehensive epicardial echocardiography examination: recommendations of the American Society of Echocardiography and the Society of Cardiovascular Anesthesiologists. J Am Soc Echocardiogr. 2007; 20(4):427-37. https://doi.org/10.1016/j.echo.2007.01.011.
15. Pignatti M, Mantovani F, Bertelli L, et al. Effects of silicone expanders and implants on echocardiographic image quality after breast reconstruction. Plast Reconstr Surg. 2013;132(2):271-8. https://doi.org/10.1097/PRS. Ob013e31829e7bec

\section{Publisher's Note}

Springer Nature remains neutral with regard to jurisdictional claims in published maps and institutional affiliations.

\section{Ready to submit your research? Choose BMC and benefit from:}

- fast, convenient online submission

- thorough peer review by experienced researchers in your field

- rapid publication on acceptance

- support for research data, including large and complex data types

- gold Open Access which fosters wider collaboration and increased citations

- maximum visibility for your research: over $100 \mathrm{M}$ website views per year

At BMC, research is always in progress.

Learn more biomedcentral.com/submissions 